\title{
EL HORIZONTE POLITICO DE LA INCLUSIÓN: CIUDADANÍA E INMIGRACIÓN EN ESPAÑA
}

\author{
THE POLITICAL HORIZON OF INCLUSION: CITIZENSHIP AND \\ IMMIGRATION IN SPAIN
}

\author{
Manuel Menéndez Alzamora \\ Universidad de Alicante. España/Spain \\ manuel.menendez@ua.es
}

Recibido/Received: 03/11/2011

Aceptado/Accepted: 20/02/2012

\section{RESUMEN}

El trabajo trata de establecer una propuesta de establecimiento de periodos de las diferentes oleadas de inmigración en España a partir de elementos sociales, jurídicos y políticos que se consideran de relieve. Después se traza una hipótesis sobre como considerar el último periodo de inmigración a partir de la crisis global de 2007.

\section{PALABRAS CLAVE}

Ciudadanía, participación, pluralismo.

\section{SUMARIO}

1. España ante las realidades migratorias contemporáneas. 2. Un intento de periodización a partir de factores políticos y sociales. 3. La participación política como fundamento de la co-inclusión. Bibliografía

\section{ABSTRACT}

The paper deals with a proposal for the establishment of the periods of different immigration waves in Spain from important social, political, and legal elements. Subsequently, a hypothesis is drawn concerning how to consider the period of immigration since the global crisis of 2007.

\section{KEY WORDS}

Citizenship, participation, pluralism.

\section{CONTENTS}

1. Spain faced with contemporary migratory realities. 2. An attempt at periodization from political and social factors. 3. Political participation as a basis for co-inclusion. References. 


\section{ESPAÑA ANTE LAS REALIDADES MIGRATORIAS CONTEMPORÁNEAS}

La presencia de población inmigrante en España es una realidad constatable, a los efectos de este trabajo desde hace cuatro décadas. Bien es cierto que España ha sido pieza destacable en el seno de las redes migratorias desde antes de este periodo reseñado, esto es, España ha sido emisora y receptora de población no autóctona desde antes de la década de los 70, pero la realidad inmigratoria que vamos a abordar a los efectos de este trabajo la ceñiremos temporalmente a las cuatro décadas antes reseñadas.

La presencia de población inmigrante en España desde finales de la segunda Guerra Mundial hasta principios de la década de los 60 tiene muy poca relevancia por su magnitud e impacto; desde principios de los 60 hasta mediados de los 70 España aumenta su capacidad de recepción de inmigrantes al mismo tiempo que se convierte en un país emisor de emigrantes hacia el exterior coincidiendo con la fase de expansión económica europea, un flujo migratorio que se corta a mediados de los 70 a consecuencia de la crisis económica ligada a la del petróleo que afecta a toda la economía europea, coincidiendo con los estertores del franquismo y la instauración de la democracia en España.

En otros términos, antes de la instauración democrática en España la cuestión migratoria se focaliza en torno a dos polos: el primero, más destacable por su importancia, es el fenómeno del ciudadano español inmigrante a las grandes áreas de industrialización de la boyante etapa industrial de la Europa de posguerra; el segundo polo presenta a España como lugar de recepción de inmigrantes, fenómeno de mucha menor escala y cuya principal característica, sea cual sea el origen de los inmigrantes, es que la razón que empuja a estos inmigrantes a alcanzar nuestro territorio no es de naturaleza económico-laboral.

Muchos de estos inmigrantes llegan a España por razones políticas, como es el caso de los inmigrantes iberoamericanos que escapan de las dictaduras de sus naciones, siendo destacable el contingente de ciudadanos argentinos que huyen del régimen dictatorial de su país. Este contingente de argentinos llegados tras la dictadura militar por razones políticas es reseñable no por ser numeroso en su magnitud, sino por su impacto en la vida cultural española: muchos de estos recién llegados del otro lado del Atlántico fueron protagonistas en el mundo académico, editorial y musical, generando una apertura a la pluralidad cultural en los momentos previos a la Transición. En esta misma categoría, aunque por razones político-ideológicas evidentemente opuestas, se puede encuadrar el contingente de ciudadanos europeos que colaboraron con los regímenes totalitarios que encuentran, bajo las circunstancias jurídico-políticas de la España del franquismo, un espacio ideal para un asentamiento que ofrezca ciertas garantías de impunidad.

En torno a estos dos ejes centrales se pueden analizar los flujos migratorios antes del advenimiento de la democracia. No con carácter de exclusividad porque antes de mediados de la década de los setenta también se detectan flujos migratorios de carácter parcial, temporal o germinal, como: a) el fenómeno de los pied-noirs en la zona del Levante (Sempere, 1998); b) el incipiente asentamiento de clases pasivas europeas a lo largo de una costa del Mediterráneo descubierta para las clases medias europeas en el boom turístico de la década anterior - coincidiendo con la fase de cierta apertura del régimen de Franco hacia el exterior-, es decir, parte de los visitantes vacacionales en los sesenta en plena edad laboral, empiezan a pensar en convertir el lugar de destino turístico en el de asentamiento tras la jubilación; c) por último, también se puede incluir en este apartado las migraciones laborales temporales agrícolas, los populares desplazamientos de trabajadores a la vendimia francesa. No obstante, como hemos recalcado, los problemas de migraciones en 
la España pre-democrática están fundamentalmente ligados a los problemas de emisión y posterior recepción del trabajador español que ha emigrado por razones estrictamente laborales a Alemania, Suiza o Francia.

A fin de analizar lo que acontecerá a partir de la instauración de la democracia y en fases sucesivas durante las décadas de los ochenta y los noventa hay que dejar constancia de un hecho relevante: la gran diferencia que existe entre España y otras naciones de nuestro entorno cultural en Europa -Francia y Gran Bretaña fundamentalmente, Alemania en menor medida- en orden a la consideración del extranjero, del otro, del diferente, desde múltiples niveles. Las grandes naciones colonizadoras del siglo XIX son receptoras de importantes contingentes de población provenientes de sus colonias en África y Asia. Este flujo de desplazamientos hacia la metrópolis cobra intensidad y magnitud conforme estas colonias logran su propia soberanía nacional en el proceso de descolonización que abarca las décadas centrales del siglo pasado. Este flujo de migración colonial hacia Europa tiene gran impacto a partir del fin de la II Guerra Mundial y durante la década de los cincuenta, momento en el que miles de personas se desplazan hacia unas naciones que, tras la posguerra bélica, sientan las bases del nuevo Estado Social. Los barrios coloniales en las grandes ciudades británicas y francesas se configuran como un nuevo espacio político y crean un nuevo imaginario social en los ciudadanos autóctonos. La cuestión del otro comienza a ser abordada desde el ámbito político, social, académico y lentamente se introduce en las agendas políticas de los partidos y otros actores sociales, como por ejemplo los sindicatos.

Para la España que a mediados de los setenta se enfrenta al reto de la Transición política la posibilidad de que la sociedad española dejase de ser homogénea en un momento no muy lejano resultaba una posibilidad remota, y, de tan remota, casi inimaginable. Esta circunstancia condicionará parte de la realidad posterior, y en lo que nos atañe se manifiesta en la manera en que se abordan algunos derechos del Título I de la Carta Magna de 1978. Contando con la realidad sociológica posterior, el constituyente se habría colocado en la obligación de matizar cuestiones como la titularidad de derechos, por ejemplo, que posteriormente han sido matizadas por la jurisprudencia a través de la remisión a declaraciones de derechos de rango superior; en otras palabras, el universalismo de los derechos hubiera sido ceñido textualmente de otra manera.

\section{UN INTENTO DE PERIODIZACIÓN A PARTIR DE FACTORES POLÍTICOS Y SOCIALES}

Una vez instaurada la democracia el problema de las migraciones protagoniza un giro diferenciado. Para su abordaje vamos a intentar establecer tres grandes etapas de referencia dado que la realidad de los procesos migratorios en España está muy condicionada por la línea de temporalidad dentro de la cual se inscribe.

En primer lugar afirmaremos que, ya en este nuevo período, la cuestión de la migración en España es una cuestión casi exclusivamente de inmigración. España cobra gran protagonismo como país receptor de ciudadanos en la misma medida que progresivamente deja de tenerlo como emisor. Una segunda idea fundamental nos hace ver que la nueva inmigración tiene naturaleza económico-laboral, las razones políticas e incluso las culturales dejan de tener la relevancia de antaño. 
Aunque alguna de las temporalizaciones más destacadas plantea un periodo que iniciándose en los 70 llegaría hasta 1985, nosotros proponemos una primera gran fase que, arrancando en 1978 alcanzaría hasta 1992. Son catorce años desde la aprobación de la Constitución hasta el popular 92. Tomamos este último año como referencia por ser el año en el que España se convierte en protagonista de dos grandes eventos de carácter global: las Olimpiadas de Barcelona y la Expo de Sevilla, acontecimientos que ponen de largo una imagen de España triunfante, con los restos del anterior régimen en fase de avanzada eliminación, con una economía en crecimiento y ligada a un ciclo positivo de la economía global. Aunque es un lugar común no dejamos de afirmar algo que a los fines del ámbito de este trabajo tiene gran importancia: España muestra una imagen al mundo de plena integración en la modernidad convirtiéndose en objeto de deseo desde el punto de vista laboral y del status social. En este gran periodo tienen lugar los dos primeros grandes procesos de regularización de extranjeros -1985-86 y 1991-92-, e igualmente es el periodo en el que entra en funcionamiento la Ley de Extranjería de 1985 (Ley Orgánica 4/2000, de 11 de enero, sobre derechos y libertades de los extranjeros en España y su integración social).

Este primer período está caracterizado por la llegada a España de un inmigrante europeo y en menor medida latinoamericano. Se trata de una inmigración en la que se mezclan las razones políticas, muy destacables en los inmigrantes latinoamericanos, con las motivaciones económico-laborales. Como señala el profesor Cachón una de las características más destacables sería la muy reducida presencia de inmigrantes magrebíes (Chacón, 2002:104).

El segundo periodo lo hacemos transcurrir entre 1992 y el año 2007. Este periodo viene marcado en su punto de arranque, y a modo de bisagra con el periodo anterior, por dos fenómenos históricos de gran importancia para el análisis de la inmigración en España: la caída del Muro de Berlín en 1989 y la posterior desintegración de la antigua Unión Soviética a partir de 1991. Se trata de dos factores históricos que tienen una naturaleza determinante en el periodo que ahora vamos a analizar. Esta fase tiene una gran importancia fundamentalmente por su magnitud, durante los quince años que median entre los eventos del 92 y el inicio de la gran crisis económica en el otoño de 2007, España se convierte en un lugar de llegada masiva de inmigrantes convirtiendo esta circunstancia en una nueva realidad social.

En cuanto a su naturaleza hay que destacar dos elementos fundamentales, en primer lugar se trata de una inmigración de naturaleza laboral, desapareciendo las razones de naturaleza política o cultural, en segundo lugar, y respecto a los lugares de procedencia, se diferencian tres grandes apartados; en primer lugar, un gran bloque de origen latinoamericano, en segundo lugar, un bloque de origen africano, dentro del cual se podría diferenciar netamente un contingente de origen magrebí y otro de naturaleza subsahariana; en tercer lugar, aparece de manera novedosa un bloque de inmigración europea fundamentalmente proveniente de los países del Este, combinado con una pequeña parte correspondiente a la inmigración europea de la tercera edad, en este caso se trata de razones laborales no en su sentido activo sino pasivo, esto es la consideración de España como lugar de asentamiento de pensionistas de la Europa del Norte que hemos comentado anteriormente.

En este periodo la inmigración se convierte en una cuestión que va a requerir un tratamiento jurídico específico, una implementación de nuevas políticas públicas destinadas a la inmigración $y$, fundamentalmente, el fenómeno de la inmigración se convierte en una cuestión que cobra entidad propia en su percepción social. El llamado 
"fenómeno de la inmigración" no sólo se visibiliza de manera cuantitativa en las estadísticas de población laboral, ahora también se constata al pasear por las ciudades o al recorrer los barrios multiétnicos en los grandes núcleos de población, el inmigrante es ahora un nuevo sujeto social que se integra con el resto de ciudadanos, la presencia de población extranjera, la presencia del otro, es algo que la sociedad española va a interiorizar de manera progresiva desde el arranque de la década de los 90.

La incorporación del inmigrante en el imaginario socio-cultural del ciudadano español se produce de manera ambivalente: de una parte la manera expansiva y abierta de manifestarse que caracteriza a la cultura española facilita el proceso de integración pero, al mismo tiempo, a) el aumento de la masa inmigratoria con la subsiguiente aparición de barrios étnicos más cerrados, b) la previsión de disputa en el mercado laboral; y c) las cuestiones de orden público en las que se suele identificar al inmigrante con el malhechor de forma gravosamente comparativa con el nacional; todas estas circunstancias, confluyen en una nueva percepción del inmigrante como problema. Todo esto hace que la cuestión de la inmigración empiece a formar parte de las agendas de los partidos políticos y que la cuestión de la inmigración sea elevada por los ciudadanos como una cuestión de preocupación tal y como lo reflejan el barómetro periódico del CIS, en las que el tema de la inmigración alcanza su mayor nivel, de entre los problemas que percibe la sociedad española. En el barómetro en el que se pregunta por los tres principales problemas a elegir entre un amplio elenco, la inmigración alcanza las cotas más altas en el historial de las oleadas del barómetro en la encuesta de septiembre de 1996, con un 59,2\% y en octubre del mismo año con un 40,0\% (Barómetro CIS: 1996): 1996 es el año que se sitúa en el centro del este segundo periodo dentro del cual tienen lugar tres grandes procesos de regularización en los años 96-2000 y 2001, y la aprobación de la Ley de Extranjería del año 2000 (Ley Orgánica 8/2000 de 22 de diciembre) que modifica la ley de 1985.

Por último, una tercera etapa que se iniciaría con el comienzo de la crisis económica y de la gran recesión, y cuyo punto final no podemos plantear sino como hipótesis, quizás podría cubrir una década hasta el año 2016 cuando algunas encuestas actuales prevén un giro sostenido positivo en las tasas de desempleo.

\section{LA PARTICIPACIÓN POLÍTICA COMO FUNDAMENTO DE LA CO- INCLUSIÓN}

La integración política y social de los inmigrantes en la sociedad receptora pasa por varias fases que se mantienen, en cierta medida, invariables en diferentes contextos. En el planteamiento de Dassetto (1990) el primer momento es el de la precariedad laboral y la marginalidad social, el segundo momento sería el de la primera integración cultural y la protección dada por las políticas sociales destinadas a los inmigrantes, mientras que el tercer momento se correspondería con la progresiva equiparación entre inmigrantes y ciudadanos autóctonos. En otras palabras todo proceso de inmigración pasaría por un circuito de integración, progresivo, que partiría de un momento de alegalidad o ilegalidad jurídica y la marginalidad social para de manera continua ir sumando peldaños en la integración y en la inclusión, en una curva ascendente que tendería hacia un punto en el que los inmigrantes y los autóctonos tendrían el mismo peso específico en la esfera pública, esto es, gozarían ambos de plenos derechos sociales y políticos, incluidos los de participación política. 
Resulta evidente que el gran período de la inmigración española 1992-2007 engloba las dos fases del ciclo migratorio propuesto por Dassetto, el paso de la marginalidad jurídica y social a la primera integración social. Si observamos el año 1996, tomado por referencia por el impacto de la inmigración en la encuesta del CIS, observamos que al final de la década de los 90 y durante el principio del nuevo siglo, una vez superada la primera fase de normativización de los elementos socio-laborales de los inmigrantes, surgen con fuerza diversos modelos de políticas sociales, impulsados desde las instituciones autonómicas y locales, fundamentalmente, que tienen como objetivo realizar el tránsito desde la mera integración jurídico-positiva a la integración social. Las políticas específicamente enfocadas a la población inmigrante en materias como educación, mujer y sanidad, se integran progresivamente en las agendas políticas de los partidos.

Sin embargo, el gran reto social consiste en la plena integración de los nuevos ciudadanos de tal manera que el diálogo de tú a tú se convierta en un diálogo realizado en el mismo plano de igualdad. Nos estamos refiriendo al proceso de verdadera inclusión del inmigrante en el tejido cultural y político de la sociedad receptora. En el caso español este proceso se desarrolla en un momento crítico puesto que coincidiría con el último momento del periodo 1992-2007 y los primeros años de la etapa que arranca con la gran crisis económica. Se trata de un momento crítico puesto que la fase que necesita de mayor energía de cohesión social, es decir, la fase de co-inclusión, se superpone en el tiempo con el declive económico y con dos efectos letales del mismo: primero el impactante descenso de las partidas destinadas en los presupuestos públicos a las políticas de integración social de los inmigrantes y, en segundo lugar, la colisión de intereses laborales y de prestación social entre los autóctonos y los inmigrantes. En este complicado escenario vamos a analizar tres elementos que consideramos fundamentales para comprender desde el punto de vista económico los retos que la co-inclusión planteará en nuestro futuro inmediato. En primer lugar la progresiva adquisición de los derechos de ciudadanía por parte de los inmigrantes, en segundo lugar los problemas de rechazo a la co-inclusión que tienen su plasmación más visible en la aparición de partidos de naturaleza xenófoba, por último abordaremos la cuestión de la integración educativa y lingüística como parámetro fundamental para valorar la co-inclusión.

En el ámbito de los derechos fundamentales se puede afirmar que el núcleo duro de los derechos fundamentales contemplados en el Título I de la Constitución extiende su titularidad a toda persona sea nacional o extranjera, autóctona o emigrante. Nuestra Carta Magna se elaboró en un momento en el que el problema de la inmigración no tenía un impacto significante, el constituyente no contó con ese profundo giro en la realidad sociológica española, sin embargo los derechos fundamentales por su propia naturaleza universalista y por ser reflejo constitucional de derechos de primer nivel contenidos en declaraciones de derechos, tienen un sujeto titular universal. Más dudas se plantean entorno a la titularidad de otros derechos característicos del Estado Social, son los llamados derechos de prestación o los de tercera generación, aquí las posiciones doctrinales son más variadas y oscilan entre el reconocimiento universal y sin distinción de estos derechos, a posiciones más restrictivas fundamentadas en la naturaleza prestataria de estos derechos y en los presupuestos limitados para proveerlos (García, 2004:171-197).

Un elemento clave para valorar en que medida los derechos fundamentales integran en igualdad de condiciones a los nuevos ciudadanos consiste en testar la integración en orden a usar activamente los llamados derechos políticos de participación y representación. En el ámbito de la representación los extranjeros han avanzado sustancialmente en el reconocimiento de derechos en las elecciones locales. En estos procesos electorales tienen 
capacidad activa y pasiva de voto todos los miembros de la UE más aquellos de terceros países (Noruega encabezó está posibilidad) que tengan suscritos convenios de reciprocidad con España en esta materia. Como ha señalado Ainhoa Uribe esta posibilidad no genera movimientos destacables en los resultados electorales, y sólo en aquellos casos en los que se convergen dos circunstancias: por un lado, una muy alta concentración de extranjeros en el censo electoral de un municipio y, por otro lado, un ciudadano extranjero políticamente implicado, o cuanto menos interesado, en la vida política de su municipio; sólo bajo estas circunstancias que se dan en la realidad en escasos municipios - por ejemplo, en algunos de la Marina Alta en la Comunidad Valenciana- el ejercicio de derechos electorales por extranjeros tiene un impacto reseñable (Uribe, 2999: 334-352).

Estos derechos no son únicamente aquellos que permiten a los ciudadanos participar activa y pasivamente en los procesos electorales. Creemos que deben abarcar de la misma manera la puesta en práctica por parte de los ciudadanos inmigrantes de otros derechos previos a los procesos electorales como son los derechos a la libertad de expresión, el derecho de reunión y el derecho de asociación. En estos derechos más relacionados con un sentido global y genérico de participación política observamos una normalización progresiva tanto en el movimiento organizativo como asociativo; los inmigrantes utilizan las herramientas de la asociación de manera activa como así los demuestras las diferentes iniciativas locales y autonómicas.

En segundo lugar destacábamos que el proceso de co-inclusión en circunstancias coyunturales adversas, crisis económica y limitaciones extrema de mercado laboral implica el riesgo de la aparición de movimientos reactivos. En otras palabras, se trataría de la aparición del rechazo al diferente en unos momentos en donde el ciudadano autóctono se siente desplazado, en la periferia de la atención institucional y necesitado de un reforzamiento de su autoestima identitaria con el objeto de reafirmarse emocionalmente como miembro de una comunidad. Este rechazo presenta múltiples enfoques, existe un rechazo silencioso e intrasocial que surge de manera aparentemente esporádica cuando los ciudadanos autóctonos, por ejemplo, escolarizan a los niños en centros educativos sin inmigrantes.

Pero este rechazo también tiene una expresión fuerte con la aparición de movimientos políticos de naturaleza xenófoba. Este último fenómeno ha surgido con fuerza en diversos países europeos (Innerarity y Acha, 2010). En España la irrupción del activismo político partidista xenófobo no ha alcanzado a las instituciones representativas de ámbito nacional, pero sí lo ha hecho en las de ámbito local, donde algunos partidos políticos de esta naturaleza han alcanzado representación municipal, especialmente en Cataluña y la Comunidad Valenciana (Uribe, 1999:347-348). La literatura politológica en el ámbito del radicalismo excluyente y extremo muestra el creciente interés por esta cuestión (Kitschelt, 1995 y Hainsworth, 2000), el factor inmigración ha de ser considerado uno de los elementos que explican la irrupción con gran fuerza en el mercado electoral de partidos de extrema derecha pero, como ha señalado Pippa Norris, en el ascenso electoral de estos partidos confluyen muy diversos factores de naturaleza social y económica, al mismo tiempo que estos partidos modelan su acción y mensaje según los sistemas electorales -proporcionales o mayoritariosa fin de rentabilizar los votos obtenidos al máximo; por todo ello la ecuación inmigración ascendo partidista radical debe ser tomada desde una perspectiva multinivel (Norris, 2005).

Por último, y en lo relativo a la co-inclusión plena, destacamos una cuestión de relevancia trascendental. Tanto la integración educativa, como el ejercicio de derechos relativos a la participación política, pasan por un momento condicionante fundamental, nos referimos a la plena integración lingüística de los inmigrantes en el entorno de recepción. El compartir una 
misma lengua es el presupuesto básico para poder compartir una misma esfera pública, el estudio de Echarranza sobre la base de la Encuesta Social Europea resulta muy clarividente (Echarranza, 2011:57-77). La vinculación entre participación política de los ciudadanos inmigrantes (Moya y Viñas, 2010) e integración lingüística es evidente.

\section{BIBLIOGRAFÍA}

BARÓMETRO CIS: http://www.cis.es/cis/opencm/ES/11_barometros/index.jsp

CHACÓN RODRÍGUEZ, L. (2002), "La formación de la España inmigrante: mercado y ciudadanía", Revista española de investigaciones sociológicas, $\mathrm{n}^{\circ} .9$

DASSETTO, F. (1990), "Pour une théorie des cycles migratories", en Basteiner, A. y Dassetto, F. (eds.), Inmigrations et nouveaux pluralismes. Une confrontations de sociétés. Bruselas: De BoeckWesmael, pp. 75-111.

ECHARRANZA, A. (2011), "La incorporación política de los nuevos ciudadanos: participación electoral y origen inmigrante", Revista Española de Ciencia Política, nº. 25, pp. 57-77.

GARCÍA AÑÓN, J. (2004), "Medidas antidiscriminatorias y derechos de los inmigrantes" en: AÑÓN, M. J. (ed.), La universalidad de los derechos sociales: el reto de la inmigración. Valencia: Tirant lo Blanch, pp. 171-197.

HAINSWORTH, P. (ed.) (2000), The politics of the extreme right. Nueva York: Pinter.

INNERARITY GRAU, C. y ACHA UGARTE, B. (2010), "Los discursos sobre ciudadanía e inmigración en Europa", Política y Sociedad, vol. 47, n. 2, pp. 63-84.

KITSCHELT, H. (1995), The radical right in Western Europe. Ann Arbor: University of Michigan Press, 1995.

MOYA, D. y VIÑAS, A. (eds.) (2010), Sufragio y participación política de los extranjeros extracomunitarios en Europa. Barcelona: Fundació Carles Pi i Sunyer.

NORRIS, P. (2005), Radical Right. Voters and parties in the electoral market. Cambridge: Cambridge University Press.

SEMPERE SOUVANNAVONG, J. D. (1998), Los "pieds-noirs" en Alicante: las migraciones inducidas por la descolonización. Alicante: Universidad de Alicante.

\section{Breve currículo:}

\section{Manuel Menéndez Alzamora}

Licenciado y Doctor en Derecho por la Universitat de València. Profesor de Ciencia Política y de la Administración en la Universidad de Alicante y autor de diferentes libros dedicados al pensamiento político entre los que destacan La generación del 14 (Madrid, Siglo XXI, 2006), Premio Nacional de la Asociación Española de Ciencia Política (AECPA) al mejor libro editado en 2006 y el XI Premio Nacional Ángel Herrera 2007 al mejor trabajo de investigación. Editor único y coautor de los libros: Sobre el poder (Madrid, Tecnos, 2007) y Participación y representación política (Valencia, Tirant lo Blach, 2008). Igualmente es coautor de otros libros entre los que destacan: Política de la vitalidad (Madrid, Tecnos, 1996) y Política y sociedad en José Ortega Gasset: En torno a "Vieja y nueva política” (Barcelona, Anthropos, 1997). También es autor de artículos en revistas especializadas, capítulos en obras colectivas y trabajos en actas de congresos nacionales e internacionales. 